\title{
Improving Transparency in the Reporting of Safeguards Implementation: FY11 Update
}

CM Toomey

ET Wyse

CS Odlaug

September 2011

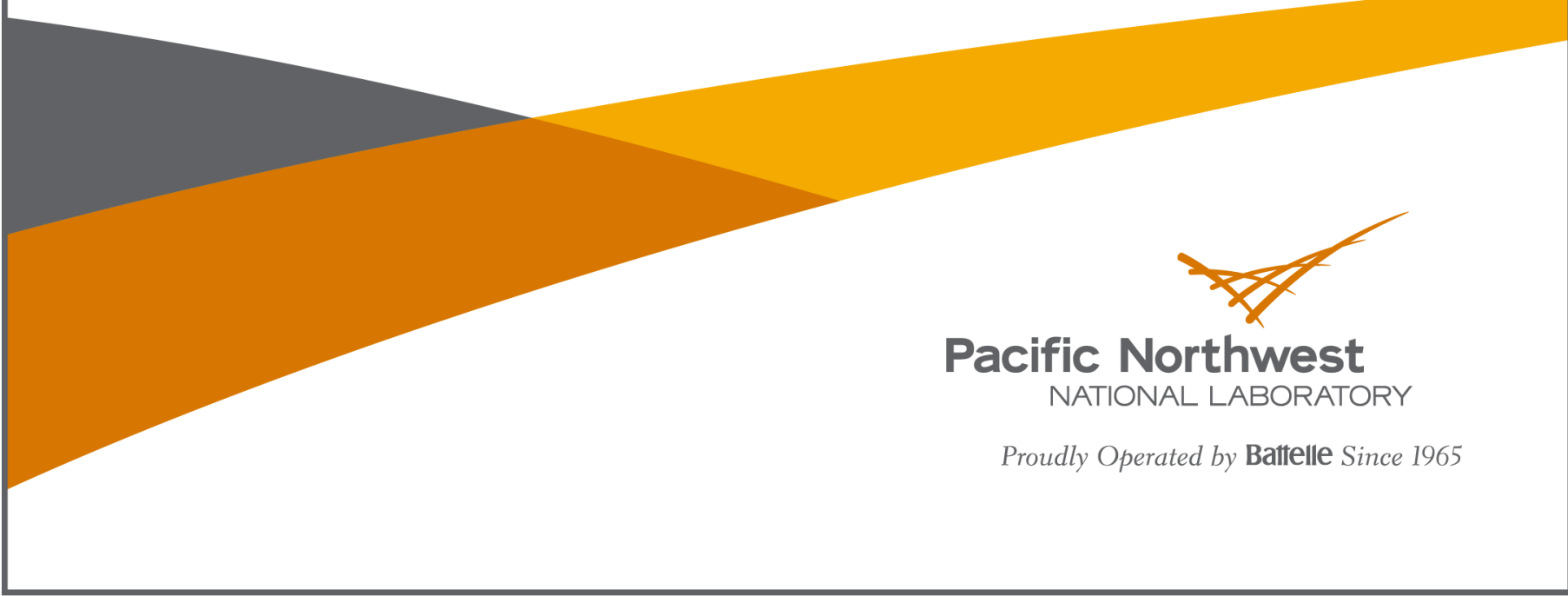




\title{
DISCLAIMER
}

This report was prepared as an account of work sponsored by an agency of the United States Government. Neither the United States Government nor any agency thereof, nor Battelle Memorial Institute, nor any of their employees, makes any warranty, express or implied, or assumes any legal liability or responsibility for the accuracy, completeness, or usefulness of any information, apparatus, product, or process disclosed, or represents that its use would not infringe privately owned rights. Reference herein to any specific commercial product, process, or service by trade name, trademark, manufacturer, or otherwise does not necessarily constitute or imply its endorsement, recommendation, or favoring by the United States Government or any agency thereof, or Battelle Memorial Institute. The views and opinions of authors expressed herein do not necessarily state or reflect those of the United States Government or any agency thereof.

\author{
PACIFIC NORTHWEST NATIONAL LABORATORY \\ operated by \\ BATTELLE \\ for the \\ UNITED STATES DEPARTMENT OF ENERGY \\ under Contract DE-AC05-76RL01830
}

Printed in the United States of America

\author{
Available to DOE and DOE contractors from the \\ Office of Scientific and Technical Information, \\ P.O. Box 62, Oak Ridge, TN 37831-0062; \\ ph: (865) 576-8401 \\ fax: $(865)$ 576-5728 \\ email: reports@adonis.osti.gov
}

\begin{abstract}
Available to the public from the National Technical Information Service, U.S. Department of Commerce, 5285 Port Royal Rd., Springfield, VA 22161 ph: (800) 553-6847 fax: (703) 605-6900

email: orders@ntis.fedworld.gov

online ordering: http://www.ntis.gov/ordering.htm
\end{abstract}

This document was printed on recycled paper.

$(9 / 2003)$ 


\title{
Improving Transparency in the Reporting of Safeguards Implementation: FY11 Update
}

\author{
CM Toomey \\ ET Wyse \\ CS Odlaug
}

September 2011

Prepared for

the U.S. Department of Energy

under Contract DE-AC05-76RL01830

Pacific Northwest National Laboratory

Richland, Washington 99352 



\begin{abstract}
In 2008, the Standing Advisory Group on Safeguards Implementation (SAGSI) indicated that the International Atomic Energy Agency's (IAEA) Safeguards Implementation Report (SIR) has not kept pace with the evolution of safeguards and provided the IAEA with a set of recommendations for improvement. The SIR is the primary mechanism for providing an overview of safeguards implementation in a given year and reporting on the annual safeguards findings and conclusions drawn by the Secretariat. As the IAEA transitions to State-level safeguards approaches, SIR reporting must adapt to reflect these evolutionary changes. This evolved report will better reflect the IAEA's transition to a more qualitative and information-driven approach, based upon State-as-a-whole considerations. This paper applies SAGSI's recommendations to the development of multiple models for an evolved SIR and finds that an SIR repurposed as a "safeguards portal" could significantly enhance information delivery, clarity, and transparency. In addition, this paper finds that the "portal concept" also appears to have value as a standardized information presentation and analysis platform for use by Country Officers, for continuity of knowledge purposes, and the IAEA Secretariat in the safeguards conclusion process. Accompanying this paper is a fully functional prototype of the "portal" concept, built using commercial software and IAEA Annual Report data and available for viewing at http://safeguardsportal.pnnl.gov.
\end{abstract}





\section{Contents}

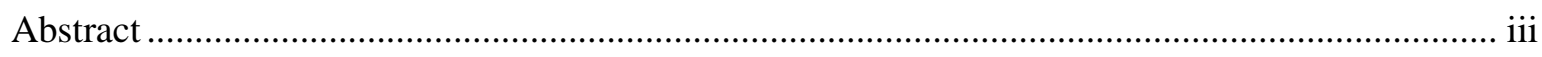

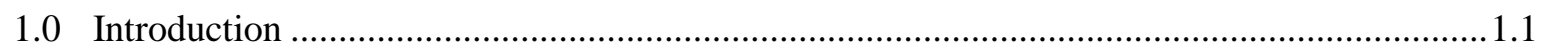

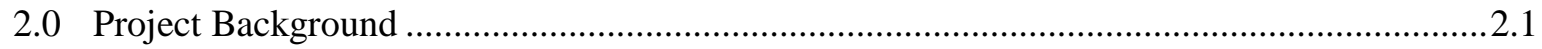

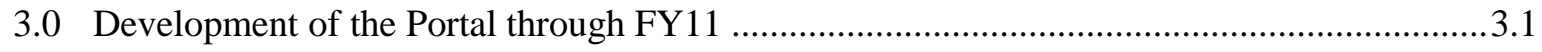

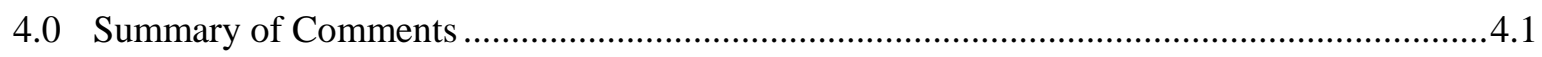

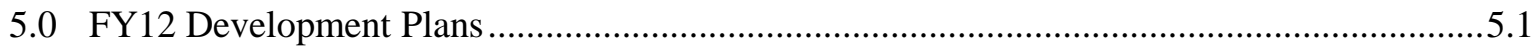





\subsection{Introduction}

The International Atomic Energy Agency's (IAEA) safeguards system is evolving from a criteriabased system with a focus on declared nuclear materials and facilities to a more information-driven StateLevel Concept (SLC) that examines all nuclear activities within the State. This approach includes the collection and analysis of information about a State from a variety of open sources, visits at locations not containing nuclear material, and evaluation of the consistency of a State's nuclear programs. As a result, it has become increasingly important, and simultaneously challenging, to improve the transparency of the complex planning, implementation, and evaluation process in ways that facilitate confidence in the IAEA's safeguards conclusions.

The Safeguards Implementation Report (SIR) is the primary mechanism reporting on the annual safeguards findings and conclusions drawn by the Secretariat. As such, there is an implied requirement for it to be constructed and presented in such a manner as to engender confidence in those conclusions. To meet this requirement, the SIR must include not only qualitative and quantitative types of data, but also present data and information in a format that is sufficiently transparent and accessible to facilitate confidence in the conclusions contained therein.

In FY10, NNSA's Office of Nuclear Safeguards and Security commissioned the Pacific Northwest National Laboratory (PNNL) to explore options for improving the transparency of safeguards reporting. In FY10, PNNL delivered a report on the subject and prepared a mocked-up demonstration of a Safeguards Information Portal using a commercial software toolset. Reviewers concluded that the demonstration had merit in terms of improving the development of the SIR and recommended further development of the Safeguards Information Portal. However, they agreed that in its current format, and using SIR-based information, the Safeguards Information Portal was not suitable for broad consumption. In order to fully test the capabilities of the Portal and socialize it to key stakeholders, reviewers recommended development of a sanitized and cost-effective version using Annual Report content. In FY11, PNNL developed a full Safeguards Information Portal using Annual Report content and presented the Portal at the 2011 INNM Annual Meeting, where it was positively received by NNSA and the IAEA.

This report is a summary of the process and findings of PNNL's FY11 work. Included in the body of the paper will be a description of the work to date, lessons learned, a summary of comments, and a description of next steps for FY12. Following the conclusions will be an appendix that includes the paper presented at the INMM Annual meeting. Additional background information can be found in the FY12 PNNL report titled, “Improving the Transparency of IAEA Safeguards Reporting," PNNL-19838. 



\subsection{Project Background}

This project was funded by the National Nuclear Security Administration's (NNSA) Next Generation Safeguards Initiative (NGSI) to evolve the SIR so as to facilitate the IAEA's ongoing transition to the SLC, improve transparency, and provide continued confidence in the IAEA's safeguard-related activities and conclusions.

Following the FY10 report to NNSA, PNNL was tasked with building a proof-of-concept website using IAEA Annual Report data, in order to facilitate broad availability with the target audience. Using the conceptual and technical guidance developed in FY 10, ${ }^{1}$ PNNL constructed a website in accordance with the "A" standard of Eisenman Associate' Online Annual Report (OAR) Grading System. This standard is as follows: ${ }^{2}$

- The OAR must be fully browsable, designed specifically for the web, and ideally offering downloadable files in their native application, such as Excel.

- Rationale: Documents designed specifically for the web are made to be viewed and read online.

- The OAR must contain at least one non-static feature, interactive chart, table, or Flash Animation.

- Rationale: Multimedia features have the potential to be much more engaging and informative than static photographs and text.

- The OAR must contain one or more videos of the CEO, executives and/or narrative content.

- Rationale: Videos show a company's personality through its people, products, services, and culture.

Using these best practices in addition to the previously-developed guidance, PNNL selected a development framework and began to construct the portal POC. The development process is described in the next section.

\footnotetext{
${ }^{1}$ For specific detail, see PNNL-19838

2 Eisenman, Nina, “2010 Online Annual Report Report,” Eisenman Associates, New York, 2010.
} 



\subsection{Development of the Portal through FY11}

To develop the portal, PNNL initially selected the Django web-development framework. Django was initially developed by an online news service to facilitate the needs of a modern newsroom with a minimal level of upkeep required. Given the time and functionality demands of the project, Django provided an expedient development environment with sufficient flexibility to integrate multiple types of information/media into the portal.

As part of the project, PNNL set the goal that the development should be as standardized and reproducible as possible, in order to provide an accurate measure of the level of effort required to formally update the SIR. PNNL made use of open-source or free-to-use technologies to emphasize that high-level of front and back-end functionality could be embedded without the expense of custom development. The following are two examples of the effort to use a commercial or standards-based approach:

1. In order to upload the text into the MySQL database and the eventually the portal, PNNL employed a Python library that can ingest Microsoft Word documents and PDFs using simple style standards such as bold, italic, underline, or user-defined Styles found in the Microsoft Office Ribbon to parse the text automatically into relevant sections. In addition, this library can automate the creation and updating process, allowing the creator to focus on content rather than worry about page length requirements.

2. To display data relevant to each section of the Annual Report, PNNL used a software tool called Tableau Public TM. Tableau Public TM is the free-to-use version of Tableau Software's Desktop Business Intelligence/Business Analysis tool. It allows a user to visualize common database formats while also providing public visualization hosting services. It provides the same level of visualization customization and functionality as the Tableau Desktop ${ }^{\text {TM }}$ software. All visualizations are Javascript-based and are thus implementable across any web development framework. In the IAEA development environment, the same effect would require a Tableau Server + Desktop environment (which has an associated procurement and maintenance cost) but the end result would be identical.

In response to some unanticipated technical difficulties, and in order to better accommodate PNNL's server environment, the site was recoded using a Hypertext Preprocessor (PHP)-based framework called Yii. The functionality and content is identical to the Python-based framework, but after discussions with the developer and hosting staff within PNNL, the switch to PHP will be a more sustainable and costeffective path for the planned development work in FY12. PHP, like Python, is a widely used development framework, so the switch to PHP will have no impact on the IAEA's ability to further develop the concept if it chooses. All of the functionality from the first Python-powered version will be preserved in the PHP-version.

During this re-coding process, the development team made the portal available to internal staff for comment. The comments are summarized in the next section. 



\subsection{Summary of Comments}

The overall response to the portal has been very positive. Anecdotally, the INMM audience felt that the concept was intuitive, accessible, and brought the IAEA's reporting into the modern era.

In addition, the overall response from PNNL staff has been positive. The following are a highlighted list of comments.

- The format is conducive to navigation, but it may be too busy and result in information overload.

- The data interactivity is excellent, and largely intuitive; but it does negatively affect page performance. Tableau dashboards were useful, although perhaps more careful integration and limitation of functionality would reduce the information overload to new users.

○ Specifically related to budgetary dashboards - they should be all integrated and linked to the year specified by the user.

- Colors need to be more standardized within a page, so as not to confuse the reader.

- Clarity of acronyms and terms needs to be easily accessible to all users.

- The document and database references need to be available on every page, with a summary page available somewhere within the website.

- Some basic instructions as to how to navigate through and within the site would be helpful at the outset.

- Searchability needs to included, so users can move quickly from one section to the next without having to hunt through massive amounts of text and data manually.

The next phase of this project will be to apply the portal concept to the 2010 SIR, taking into account all comments received to date. This follow-on work will address both the functionality and design concerns voiced during the initial comment period. The final section will summarize the planned next steps for this project during FY12. 



\subsection{FY12 Development Plans}

As concluded in FY10, and supported by the FY11 response to the demonstration, the portal concept is a viable option to assist the IAEA in improving the transparency and effectiveness of its reporting. In order to respond to the comments from PNNL staff, the project staff has sought out experts to help design and populate the third-generation of the portal.

The first concern is website design. During FY11, the team was limited to PNNL-designed style sheets. In FY12, the plan is to build the user experience and interface (UX/UI) from the ground up. We have identified a template for overall website design and brought in a UX/UI expert to work with the developer in this respect.

The second concern is overall site identity. The PNNL branding clashed with the IAEA-centric aspects of the portal. In conjunction with the UX rebuild, we will be employing a graphic designer to mimic the tone and palette of the IAEA website. This is to ensure that if/when IAEA staff evaluate the site, it is instantly apparent how this would assimilate with their current IT products.

The third concern is page performance. Due to the intensive nature of Tableau, there are controls being built into the back-end of the site in order to manage the bandwidth required for each page. In addition, the project team will be employing a demonstration version of the Tableau Server + Desktop setup that the IAEA would utilize in deploying an actual portal. This will dramatically speed up information provision as it runs within the IT environment rather than through publicly available and accessed servers.

The fourth concern is security. This was not voiced in the comment period, but is an essential component to developing a portalized SIR. The project team will be employing a user account mechanism with two-factor authentication to prevent information disclosure.

These four areas are the primary developmental foci for FY12, in addition to improving the information delivery mechanisms (i.e. the visualizations and additional information sources). The final site will be made available publicly to National Lab staff, NNSA, the interagency, the United States Mission to the International Organizations in Vienna, and the IAEA.

PNNL expects a more rigorous commenting and revision period during FY12, in order to prepare the site for additional reviews. Once delivered to NNSA, and pending approval, PNNL will work with NGSI staff to prepare a plan to demonstrate the concept to the interagency and eventually the IAEA. The final goal is to develop a version complete enough to convince the IAEA to deploy the concept in an appropriate manner. 



\section{Distribution}

No. of

Copies

4 DOE - NNSA, NA-241

1000 Independence Ave., SW

Washington, D.C., 20585-8000

Dunbar Lockwood

Marc Humphries

John Murphy

David Peranteau
No. of

$\underline{\text { Copies }}$

\section{Local Distribution}

Pacific Northwest National Laboratory

Hal Undem

PDF

Sarah Frazar

PDF

Jason Schergur

PDF

Gretchen Hund

PDF 




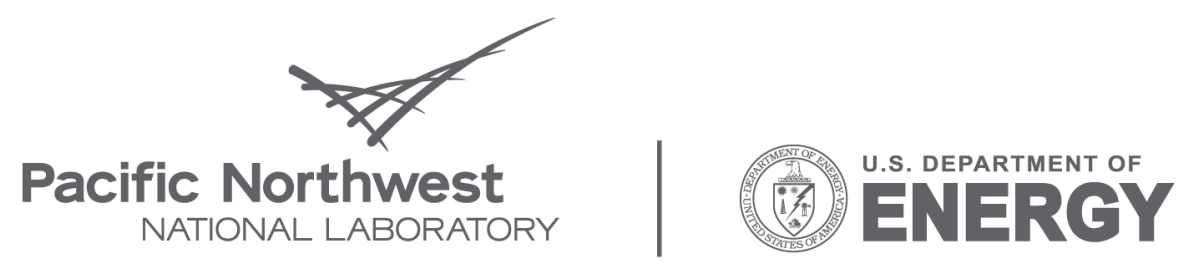

Proudly Operated by Battelle Since 1965

902 Battelle Boulevard

P.O. Box 999

Richland, WA 99352

1-888-375-PNNL (7665)

www.pnl.gov 